\title{
RANCANG BANGUN SISTEM DETEKSI DAN PEMADAM KEBAKARAN PADA SMART HOME MENGGUNAKAN METODE FUZZY
}

\author{
Saiful Anam ${ }^{1}$, Indra Dharma Wijaya ${ }^{2}$, Ridwan Rismanto ${ }^{3}$ \\ 1,2,3 Program Studi Teknik Informatika, Jurusan Teknologi Informasi , Politeknik Negeri Malang \\ ${ }^{1}$ saifulanam.id@gmail.com, ${ }^{2}$ indra.dharma@polinema.ac.id, ${ }^{3}$ rismanto@polinema.ac.id
}

\begin{abstract}
Abstrak
Kebakaran merupakan bencana nonalam yang terjadi diakibatkan adanya proses atau peristiwa nonalam seperti arus pendek listrik, kegagalan sistem, human error dan sebab lainnya. Salah satu tindakan untuk mencegah kebakaran adalah memasang sistem deteksi dan pemadam kebakaran. Namun pada beberapa kasus, sistem deteksi kebakaran konvensional memiliki masalah yang cukup signifikan yaitu sering terjadinya false alarm. Maka dari itu dibutuhkan sistem yang mampu melakukan deteksi kebakaran secara akurat dan cepat serta dapat mengatasi dari terjadinya kegagalan deteksi atau false alarm. Penelitian ini menggunakan tiga sensor yaitu sensor api, sensor suhu, dan sensor asap sebagai sumber input-an data. Perangkat Arduino sebagai pembaca data dan Raspberry Pi bertugas mengelola data lebih lanjut. Sedangkan metode yang digunakan untuk melakukan pendeteksian kebakaran adalah metode Fuzzy Sugeno dengan tiga parameter utama yaitu suhu, kepekatan asap, dan intensitas api. Dari pengujian yang telah dilakukan menghasilkan nilai respon yang sesuai dengan metode Fuzzy Sugeno berdasarkan perhitungan manual maupun sistem. Pada 15 kali pengujian menunjukkan nilai Defuzzifikasi yang sesuai berjumlah 15, nilai Defuzzifikasi tidak sesuai berjumlah 0, dan terjadi false alarm berjumlah 0. Sehingga didapatkan tingkat keberhasilan perhitungan metode Fuzzy Sugeno adalah 100\%. Sistem ini berhasil melakukan pendeteksian kebakaran dan cocok untuk diterapkan pada konsep smart home.
\end{abstract}

Kata kunci : False Alarm, Fuzzy Sugeno, Raspberry Pi, Smart Home, Sensor.

\section{Pendahuluan}

Kebakaran adalah salah satu bencana yang memiliki dampak yang cukup besar. Kebakaran bisa terjadi setiap saat tanpa ada yang bisa memprediksi, apabila tidak diatasi dengan cepat maka akan mengakibatkan kerugian yang sangat besar. Beberapa dampak yang ditimbulkan akibat bencana kebakaran yaitu luka akibat terbakar, kehilangan tempat tinggal, kehilangan harta benda, dan bahkan bisa kehilangan nyawa. Banyak faktor yang mempengaruhi terjadinya kebakaran antara lain akibat korsleting dan arus pendek listrik, kenaikan suhu dari proses mekanis sehingga menimbulkan api, dan faktor manusia atau human error yang kurang paham tentang prinsip penyebab kebakaran.

Berdasarkan data statistik dari Dinas Penanggulangan Kebakaran dan Penyelamatan Provisi DKI Jakarta, peristiwa kebakaran yang terjadi di provinsi DKI Jakarta pada tahun 2016 sudah terjadi sebanyak 1.047 kasus. Beberapa penyebabnya adalah karena listrik sebanyak 754 kasus, rokok 35 kasus, kompor 75 kasus, 183 lain lain, dan 0 untuk kasus belum diketahui, namun pada tahun 2017 kasus kebakaran meningkat sebanyak 2.055 kasus. Penyebab karena listrik sebanyak 851 kasus, rokok 33 kasus, kompor 156 kasus, 1009 lain - lain, dan 6 kasus belum diketahui [1]. Sedangkan hasil data statistik kejadian kebakaran di Indonesia pada tahun 2007, kebakaran terbanyak terjadi pada daerah rumah tinggal sebesar $65.8 \%$, pusat perbelanjaan sebesar $9.8 \%$, bangunan industri sebesar $8 \%$ perkantoran sebesar $5.6 \%$, pasar sebesar $4.8 \%$, hotel sebesar $4.6 \%$, dan bangunan lainnya sebesar $0.4 \%$ [2].

Dalam Peraturan Menteri Pekerjaan Umum Nomor : 26/PRT/M/2008 tanggal 30 Desember 2008 tentang persyaratan teknis sistem proteksi kebakaran pada bangunan gedung dan lingkungan bahwa semua jenis gedung baik hunian biasa atau gedung perkantoran harus memiliki instalasi sistem deteksi, pencegah, dan pemadam kebakaran [3]. Namun menjadi masalah besar pada jenis gedung hunian biasa (rumah/kost/asrama) yang kebanyakan tidak memiliki instalasi sistem deteksi kebakaran, sehingga apabila terjadi kebakaran akan sangat kecil kemungkinan untuk dapat terdeteksi.

Pada beberapa kasus lainnya, sistem pemadam kebakaran konvensional memiliki problem yang cukup signifikan yaitu sering terjadinya false alarm. False alarm merupakan kesalahan sistem yang mendeteksi sinyal terjadinya kondisi kebakaran yang dihasilkan dari sebab selain kebakaran [4]. Selain masalah false alarm, kebanyakan sistem pemadam kebakaran konvensional hanya bisa mendeteksi terjadinya kebakaran apabila suhu ruangan sudah mecapai titik tetap yaitu 58 derajat selsius [5]. 
Perkembangan teknologi saat ini sangat pesat dan memiliki peran yang vital dalam berbagai bidang, salah satu inovasi dalam pengembangan perangkat teknologi yang sedang tumbuh pesat adalah konsep smart home. Smart home atau rumah pintar merupakan sebuah infrastruktur yang memiliki konektivitas terhadap benda - benda yang ada di sebuah rumah sehingga dapat memperluas pemanfaatan teknologi, yang mana semua kontrol terhadap benda - benda tersebut berada dalam satu control station. Beberapa penerapan pada smart home adalah controlling syytem, security system, safety system dan masih banyak sistem kontrol yang dapat diterapkan.

Pada penelitian ini akan dibangun sebuah sistem yang dapat melakukan deteksi dan pemadaman kebakaran menggunakan metode Fuzzy Sugeno dengan tiga parameter yaitu suhu, asap dan api. Selain itu sistem ini dapat melakukan monitoring dan menerima notifikasi kebakaran melalui aplikasi telegram. Diharapkan dengan adanya sistem ini dapat membantu mencegah dan mengurangi bencana kebakaran khususnya pada bangunan hunian biasa sehingga tidak menelan kerugian hingga merenggut korban jiwa, serta menyadarkan masyarakat bahwa pentingnya memiliki instalasi sistem deteksi, pencegah, dan pemadam kebakaran.

\section{Landasan Teori}

\subsection{Kebakaran}

Kebakaran adalah suatu kejadian yang sangat tidak diharapkan oleh semua pihak karena kebakaran bukan hanya menyebabkan kerugian material tetapi juga kerugian nonmaterial. Kebakaran dapat terjadi setiap saat. Menurut National Fire Protection Association (NFPA, 1992) kebakaran adalah peristiwa yang terjadi akibat bereaksinya tiga unsur yaitu bahan bakar, oksigen dan sumber energi atau sumber panas sehingga mengakibatkan timbulnya kerugian harta benda, cidera bahkan kematian. Sedangkan menurut Peraturan Menteri Pekerjaan Umum Nomor : 26/PRT/M/2008 bahaya kebakaran adalah bahaya yang diakibatkan oleh adanya ancaman potensial dan derajat terkena pancaran api sejak awal terjadinya kebakaran hingga penjalaran api yang menimbulkan asap dan gas.

\subsection{False Alarm}

False alarm atau alarm palsu merupakan sebuah sinyal alarm kebakaran yang disebabkan oleh selain dari kebakaran dimana sistem mendeteksi adanya kebakaran dan melakukan sebuah respon [10]. Berdasarkan data yang dikutip dari Building Research Establishment (BRE) yang berjudul "Live investigations of false fire alarms" memuat laporan beberapa penyebab terjadinya false alarm mulai bulan Desember 2014 sampai Maret 2015 antara lain aktivitas tidak diketahui 374 , memasak sebanyak
169 kejadian, Memanggang roti 46 kejadian, dan merokok 41 kejadian [11].

\subsection{Fuzzy Sugeno}

Teori logika fuzzy adalah sebuah metodologi "berhitung" dengan sebuah nilai atau variabel linguistik, yang mana sebagai pengganti dari nilai bilangan. Istilah fuzzy mengacu pada sebuah sistem yang memiliki arti kabur/tidak jelas/remang remang baik secara nilai, cara kerja maupun dari deskripisinya [30]. Teori logika fuzzy di populerkan oleh Professor Lofti A. Zadeh pada tahun 1965, ia berpendapat bahwa nilai benar dan salah pada logika komputer tidak bisa menyelesaikan persamaan nilai logika yang samar - samar pada kehidupan nyata. Berdasarkan permasalahan tersebut, Lofti A. Zadeh mengembangkan sebuah logika yang dikenal sebagai logika fuzzy. Inference Fuzzy Sugeno hampir sama dengan penalaran Mamdani, hanya saja Fuzzy Sugeno ini mempunyai output (konsekuen) sistem tidak berupa himpunan Fuzzy, melainkan berupa konstanta atau persamaan linier. Metode Fuzzy Sugeno memiliki dua (2) jenis, yaitu model Orde Nol sebagai berikut:

$$
\begin{aligned}
& \text { IF }\left(X_{1} \text { is } A_{1}\right) \cdot\left(X_{2} \text { is } A_{2}\right) .\left(X_{3} \text { is } A_{3}\right) .\left(X_{4} \text { is } A_{4}\right) \ldots . .( \\
& \left.X_{n} \text { is } A_{n}\right) \text { THEN } z=k
\end{aligned}
$$

Dengan $A_{n}$ adalah himpunan Fuzzy ke-n sebagai anteseden, dan $\mathrm{k}$ adalah suatu konstanta (tegas) sebagai konsekuen.

Sedangkan Fuzzy Sugeno Orde Satu adalah sebagai berikut:

IF (X1 is A1) ... (Xn is An) THEN z $=P 1^{*} X 1+\ldots+$ $P n^{*} X n+q$

Dengan $A_{n}$ adalah himpunan Fuzzy ke-n sebagai anteseden dan $P_{n}$ adalah suatu konstanta (tegas) ke- $n$ dan q juga merupakan konstanta dalam konsekuen.

\section{Metodologi Penelitian}

Metode yang digunakan untuk melakukan perhitungan dan pengendalian deteksi kebakaran pada penelitian ini adalah metode Fuzzy Sugeno. Metode Fuzzy Sugeno diterapkan agar dapat menyimpulkan beberapa kondisi yang terjadi yaitu normal, berasap, siaga dan kebakaran. Pada metode pengembangan sistem menggunakan model Waterfall yang meliputi Analisa kebutuhan, perancangan, implementasi, pengujian dan pemeliharaan.

\section{Hasil dan Pembahasan \\ 4.1 Deskripsi Sistem}

Sistem ini memiliki tiga tahap yaitu input, proses dan output. Pada tahap input sistem menbutuhkan data dari hasil pembacaan sensor suhu DHT22, sensor asap MQ-2 dan sensor api 5 channel. 
Data dari sensor yang masih berupa data analog dibaca oleh mikrokontroller Arduino yang dikonversi menajdi data digital. Kemudian data diproses dan ditransfer kedalam database MySQL yang terdapat pada Raspberry Pi melalui kabel serial. Pada tahap proses, data didalam database diambil dan dihitung menggunakan metode Fuzzy Sugeno untuk menghasilkan nilai defuzzifikasi atau output. Tahap akhhir adalah membaca hasil output yang akan menentukan sistem mendeteksi sebuah kondisi normal atau kondisi kebakaran. Apabila sistem mendeteksi kondisi normal respon sistem tidak melakukan tindakan apapun, sendangkan pada keadaan kondisi kebakaran sistem akan menjalankan perintah untuk menghidupkan buzzer, pompa air dan akan mengirimkan notifikasi melalui aplikasi telegram. Hasil pembacaan sensor dapat dilihat dan dimonitoring melalui aplikasi web localhost maupun internet.

\subsection{Analisa Kebutuhan}

Analisa kebutuhan merupakan langkah yang harus dilakukan untuk menrumuskan dan merencanakan komponen - komponen penyusun dari sebuah sistem. Kebutuhan pada penelitian ini meliputi kebutuhan perangkat keras (Hardware) dan kebutuhan perangkat lunak (Software).

Beberapa kebutuhan software adalah sebagai berikut:

- Remote Desktop Protocol

- Arduino IDE

- $\quad$ Sublime Text

- Raspbian OS

- Python IDE

Beberapa kebutuhan hardware adalah sebagai berikut:

- Raspberry Pi 3 Model B

- Arduino Mega 2560

- Kabel Jumper

- Adapter Raspberry $\mathrm{Pi}$

- Sensor Suhu DHT22

- Senosr Asap MQ-2

- Sensor Api 5 Channel

- Kabel Serial

- Pompa Air

- Relay

- Buzzer

- Kabel power pompa air

\subsection{Desain Prototype dan Arsitertur Perangkat}

Pada desain prototype yang akan digunakan untuk simulasi kebakaran bangungan hunian biasa adalah model rumah dengan ukuran bidang $50 \mathrm{~cm} \mathrm{x}$ $50 \mathrm{~cm}$ x $50 \mathrm{~cm}$ yang terbuat dari bahan papan triplek agar tidak mudah terbakar dan rusak. Prototype ini digunakan sebagai pengganti rumah hunian biasa yang sesungguhnya dalam proses pengujian sistem. Desain dari prototype bangunan hunian biasa tampak luar adalah sebagai berikut :

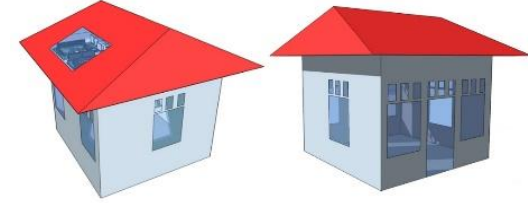

Gambar 1. Desain prototype hunian biasa

Arduino Mega terhubung dengan tiga sensor berbeda melalui kabel jumper sesuai pinout yang telah direncanakan. Raspberry Pi terhubung dengan buzzer dan relay yang terhubung dengan pompa air. Kedua perangkat tersebut terhubung melalui kabel serial untuk melakukan transaksi data. Desain arsitektur komponen adalah sebagai berikut:

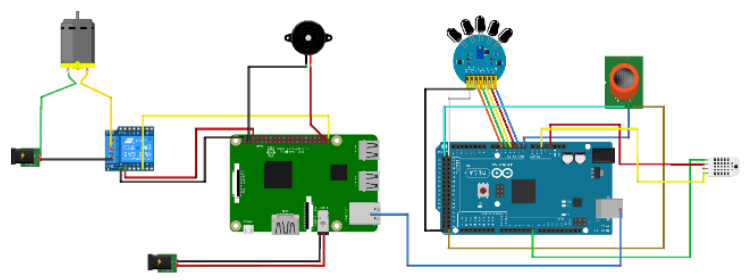

Gambar 2. Desain arsitektur komponen sistem

\subsection{Flowchart Sistem}

Flowchart pada sistem ini digambarkan pada sebuah urutan proses secara mendetail antara satu proses intruksi dengan intruksi lainnya sehingga alur sistem dapat dipahami. Berikut adalah flowchart dari sistem yang telah dibuat pada gambar dibawah ini :

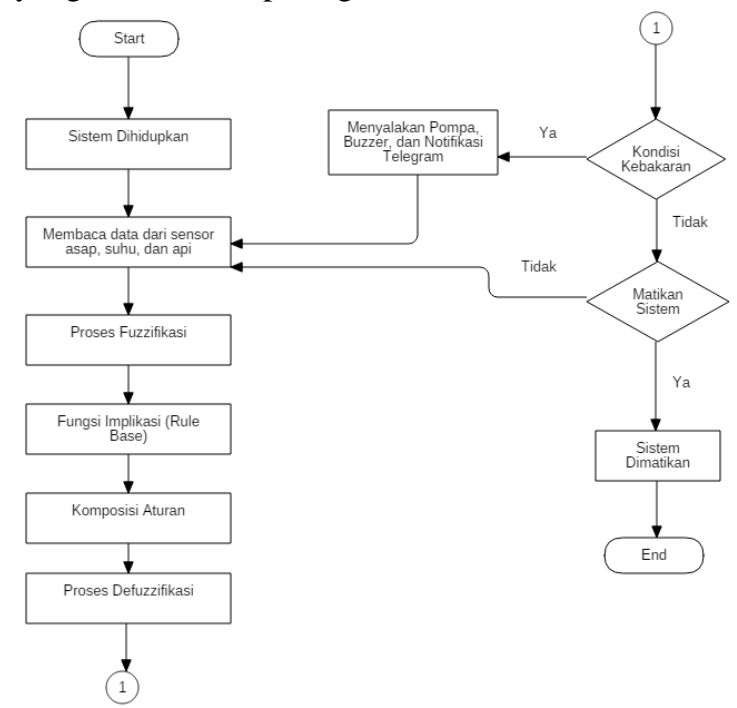

Gambar 3. Flowhart sistem

\subsection{Block Diagram}

Block diagram adalah sebuah alur pada diagram yang memetakan proses kerja dalam sistem dengan tujuan untuk memudahkan dalam mengenali komponen - komponen dan alur kerja yang ada di dalam sebuah sistem. Berikut adalah gambaran alur block diagram dari sistem. Berikut adalah block diagram yang telah dibuat pada gambar berikut ini: 


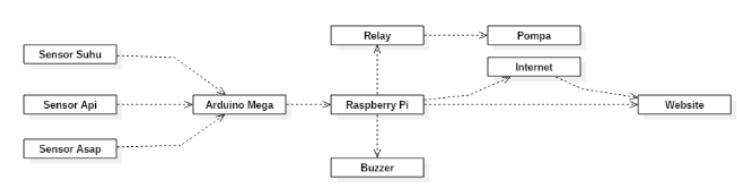

Gambar 4. Block Diagram sistem

\subsection{Metode Fuzzy Sugeno}

Berikut adalah tahapan - tahapan dari proses metode Fuzzy Sugeno, yaitu:

Fuzzifikasi, merupakan proses pengelompokan data yang bersifat tegas (Crips) kedalam himpunan Fuzzy. Kemudian menyusun domain himpunan Fuzzy dari rentang jangkauan variabel suatu himpunan. Pada penelitian ini proses fuzzifikasi memiliki himpunan keanggotaan dari tiga parameter yaitu suhu, api, dan asap. Himpunan keanggotaan suhu memiliki range normal $[10,20,30]$, sedangkan hangat $[20,30,40]$, dan panas adalah $[30,40,50]$. Berikut adalah himpunan keanggotaan pada gambar berikut :

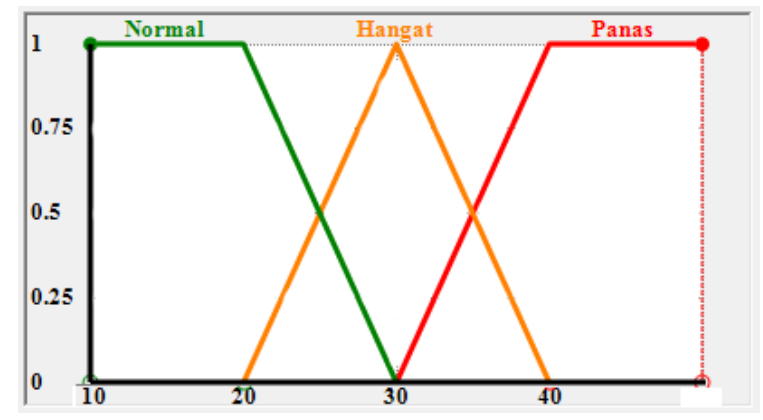

Gambar 5. Himpunan keanggotaan suhu

Himpunan keanggotaan asap memiliki range tipis $[0,25,50]$, sedang $[25,50,75]$, dan pekat $[50$, $75,100]$. Berikut adalah himpunan keanggotaan asap:

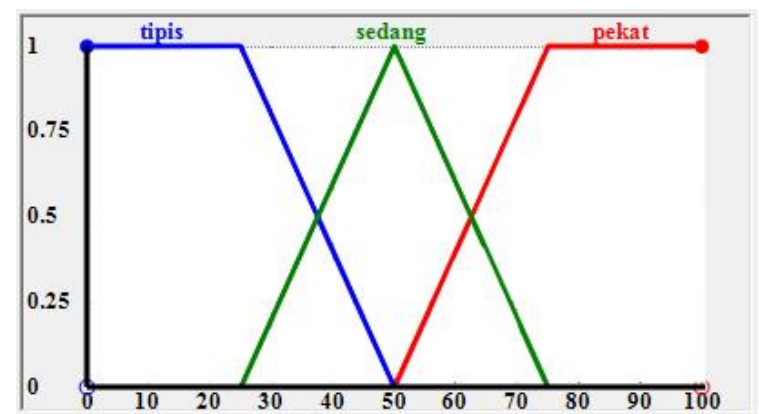

Gambar 6. Himpunan keanggotaan asap

Himpunan keanggotaan api memiliki range tidak ada api $[0,100,300]$, api kecil [100, 300, 500, 600], api sedang [400,600, 700, 900] dan api besar [700, 900, 1000]. Berikut adalah himpunan keanggotaan api :

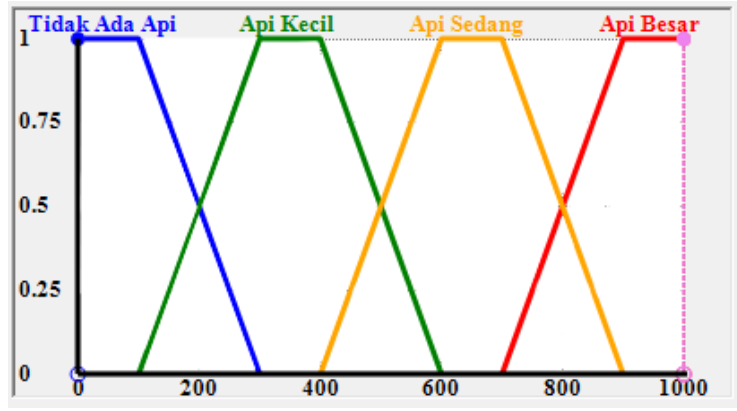

Gambar 7. Himpunan keanggotaan api

Berdasarkan himpunan keanggotaan masing masing parameter diatas, akan didapatkan nilai defuzzifikasi.

Fungsi implikasi, tiap-tiap aturan (proposisi) pada basis pengetahuan Fuzzy akan berhubungan dengan suatu relasi Fuzzy. Bentuk umum dari fungsi implikasi adalah IF x adalah A THEN y adalah B. Berdasarkan hasil variabel linguistik dalam penentuan himpunan Fuzzy, maka diperoleh aturan implikasi sebagai berikut:

Tabel 1. Fungsi Implikasi Inferensi

\begin{tabular}{|c|c|c|c|c|}
\hline To. & Suhu & Asap & Api & Kondisi \\
\hline 1 & Normal & Tipis & $\begin{array}{l}\text { Tidak Ada } \\
\text { Api }\end{array}$ & Normal \\
\hline 2 & Normal & Tipis & Api Kecil & Normal \\
\hline 3 & Normal & Tipis & $\begin{array}{l}\text { Api } \\
\text { Sedang }\end{array}$ & Normal \\
\hline 4 & Normal & Tipis & Api Besar & Siaga \\
\hline 5 & Normal & Sedang & $\begin{array}{l}\text { Tidak Ada } \\
\text { Api }\end{array}$ & Normal \\
\hline 6 & Normal & Sedang & Api Kecil & Normal \\
\hline 7 & Normal & Sedang & $\begin{array}{l}\text { Api } \\
\text { Sedang }\end{array}$ & Berasap \\
\hline 8 & Normal & Sedang & Api Besar & Siaga \\
\hline 9 & Normal & Pekat & $\begin{array}{l}\text { Tidak Ada } \\
\text { Api }\end{array}$ & Berasap \\
\hline 10 & Normal & Pekat & Api Kecil & Berasap \\
\hline 11 & Normal & Pekat & $\begin{array}{l}\text { Api } \\
\text { Sedang }\end{array}$ & Siaga \\
\hline 12 & Normal & Pekat & Api Besar & Kebakaran \\
\hline 13 & Hangat & Tipis & $\begin{array}{l}\text { Tidak Ada } \\
\text { Api }\end{array}$ & Normal \\
\hline 14 & Hangat & Tipis & Api Kecil & Normal \\
\hline 15 & Hangat & Tipis & $\begin{array}{l}\text { Api } \\
\text { Sedang }\end{array}$ & Normal \\
\hline 16 & Hangat & Tipis & Api Besar & Siaga \\
\hline 17 & Hangat & Sedang & $\begin{array}{l}\text { Tidak Ada } \\
\text { Api }\end{array}$ & Berasap \\
\hline 18 & Hangat & Sedal & Api Kecil & Berasap \\
\hline 19 & Hangat & Sedang & $\begin{array}{l}\text { Api } \\
\text { Sedang }\end{array}$ & Siaga \\
\hline 20 & Han & Sedan & Api Besar & Sia \\
\hline 21 & Hangat & Pekat & $\begin{array}{l}\text { Tidak Ada } \\
\text { Api }\end{array}$ & Berasap \\
\hline 22 & Hangat & Pekat & Api Kecil & Berasap \\
\hline 23 & Hangat & D & $\begin{array}{l}\text { Api } \\
\text { Sedang }\end{array}$ & Siaga \\
\hline
\end{tabular}




\begin{tabular}{|c|c|c|c|c|}
\hline 24 & Hangat & Pekat & Api Besar & Kebakaran \\
\hline 25 & Panas & Tipis & $\begin{array}{l}\text { Tidak Ada } \\
\text { Api }\end{array}$ & Siaga \\
\hline 26 & Panas & Tipis & Api Kecil & Siaga \\
\hline 27 & Panas & Tipis & $\begin{array}{l}\text { Api } \\
\text { Sedang }\end{array}$ & Siaga \\
\hline 8 & Panas & Tipis & Api Besar & Kebakaran \\
\hline & Panas & Sedang & $\begin{array}{l}\text { Tidak Ada } \\
\text { Api }\end{array}$ & Siaga \\
\hline 0 & Panas & Sedang & Api Kecil & Siaga \\
\hline 1 & Panas & Sedang & $\begin{array}{l}\text { Api } \\
\text { Sedang }\end{array}$ & Kebakaran \\
\hline 2 & Panas & Sedang & Api Besar & Kebakaran \\
\hline 3 & Panas & Pekat & $\begin{array}{l}\text { Tidak Ada } \\
\text { Api }\end{array}$ & Siaga \\
\hline 4 & Panas & Pekat & Api Kecil & Siaga \\
\hline$J$ & Panas & Pekat & $\begin{array}{l}\text { Api } \\
\text { Sedang }\end{array}$ & Kebakaran \\
\hline 36 & Panas & Pekat & Api Besar & Kebakaran \\
\hline
\end{tabular}

$\alpha_{i}=\mu_{A I}(X) \cap \mu_{B I}(X)=\operatorname{MIN}\left\{\mu_{A l}(X), \mu_{B I}(X)\right\}(3)$

Variable kondisi digunakan untuk menentukan nilai kondisi dari aturan implikasi yang terdiri dari kondisi normal, berasap, siaga dan kebakaran. Rentang nilai pada variabel normal dimulai dari nilai deffuzifikasi 0 sampai $\leq 0.5$, variabel berasap dari nilai defuzzifikasi $>0.5$ sampai $\leq 1.5$, variabel siaga dari nilai defuzzifikasi $>1.5$ sampai $\leq 2.5$ dan variabel kebakaran dari nilai defuzzifikasi $\geq 2.5$ sampai $\leq 3$. Berikut adalah himpunan dari variabel kondisi pada gambar dibawah ini:

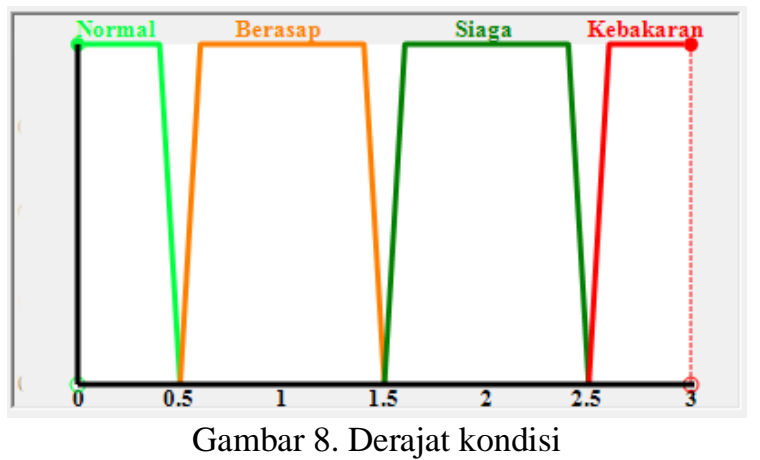

Komposisi Aturan, digunakan fungsi maksimal (MAX) untuk memperoleh solusi himpunan dengan cara mengambil nilai tertinggi dari setiap proposisi yang telah di evaluasi. Apabila semua proposisi telah di evaluasi, maka akan menghasilkan output yang berisi kesimpulan dari tiap - tiap proposisi.

$$
U s f[X i]=\operatorname{MAX}(U s f[X i], U k f[X i])
$$

\section{Keterangan :}

- $U_{s f}[X i]$ : nilai dari solusi fuzzy urutan ke $-\mathrm{i}$.

- $U_{k f}[X i]$ : nilai dari solusi fuzzy urutan ke -i.
Sehingga diperoleh nilai komposisi maksimal adalah sebagai berikut :

Normal = MAX (rule1, rule2, rule3, rule5, rule6, rule13, rule14, rule15).

Berasap = MAX (rule7, rule9, rule10, rule17, rule18, rule21, rule22).

Siaga $=$ MAX (rule4, rule8, rule11, rule16, rule19, rule20, rule23, rule25, rule26, rule27, rule 29 , rule30, rule33, rule34).

Kebakaran = MAX (rule12, rule24, rule28, rule31, rule32, rule35, rule36).

Defuzzifikasi, dalam melakukan penegasan untuk menghasilkan nilai tegas, digunakan rumus dengan cara mencari rata - rata terbobot (Weight Average) :

$$
W A=\frac{a_{1} z_{1}+a_{2} z_{2}+a_{3} z_{3}+\ldots a_{i} z_{i}}{a_{1}+a_{2}+a_{3}+\ldots i}
$$

Keterangan :

- $a_{i}$ : adalah $\alpha$-predikat ke - i.

- $z_{i}$ : adalah konsekuensi ke $-\mathrm{i}$.

\subsection{Implementasi}

\section{A. Implementasi prototype}

Implementasi prototype digunakan saat simulasi kebakaran dan pengujian. Prototype dibuat dari bahan papan triplek agar tahan terhadap suhu tinggi dan kobaran api. Model dan bentuk dibuat semirip mungkin dengan desain yang telah di rencanakan sebelumnya. Peletakan komponen sensor, perangkat Raspberry Pi dan Arduino Mega serta sprinkel disesuaikan berdasarkan desain sehingga perangkat dan kabel jumper bisa tersambung dengan baik. Berikut adalah prototype setelah dilakukan implementasi:

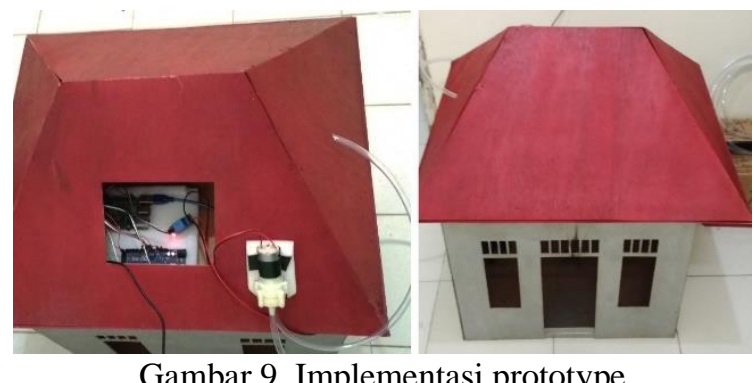

\section{B. Implementasi perancangan hardware}

Implementasi pada perancangan hardware meliputi rangkaian - rangkaian sensor, buzzer, relay dan perangkat lainnya yang saling terhubung sehingga dapat berjalan sesuai rencana. 


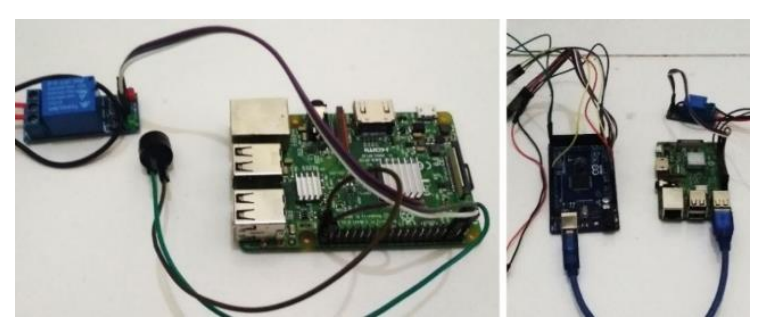

Gambar 10. Rangkaian Raspberry Pi

Rangkaian perangkat Raspberry Pi terhubung dengan relay dan buzzer menggunakan kabel jumper serta terhubung dengan Arduino Mega menggunakan kabel serial.

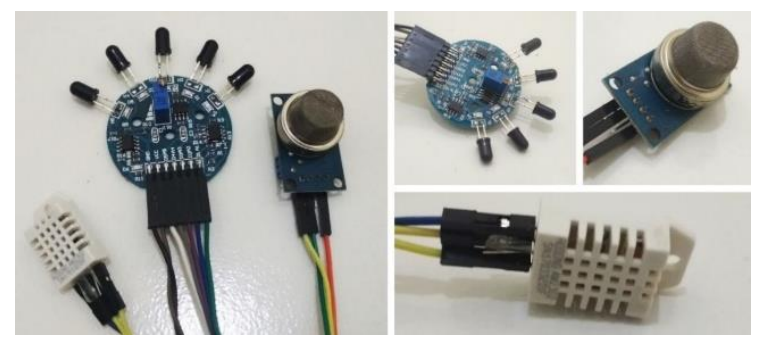

Gambar 11. Rangkaian komponen sensor

Pada rangkaian Arduino Mega terdapat tiga sensor yang tiap masing - masing sensor terhubung dengan pin melalui kabel jumper.

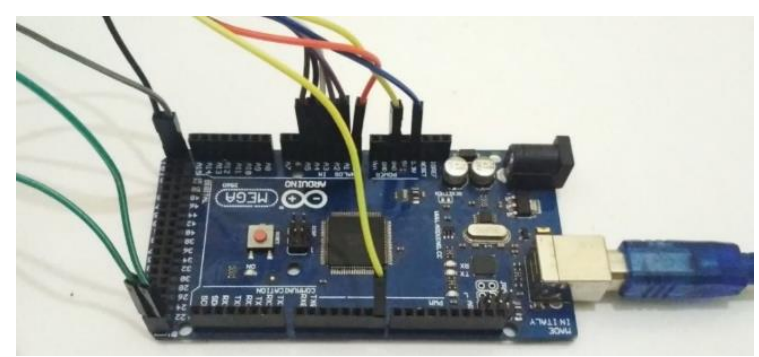

Gambar 12. Rangaian kabel jumper pada arduino mega

\section{Implementasi User Interface}

Implementasi dari tampilan antar muka atau user interface menggunakan bahasa pemrograman PHP dan dikombinasikan dengan HTML serta CSS untuk mendukung tampilan dari antar muka. Antar muka web monitoring dapat diakses melalui web browser sebagai berikut:

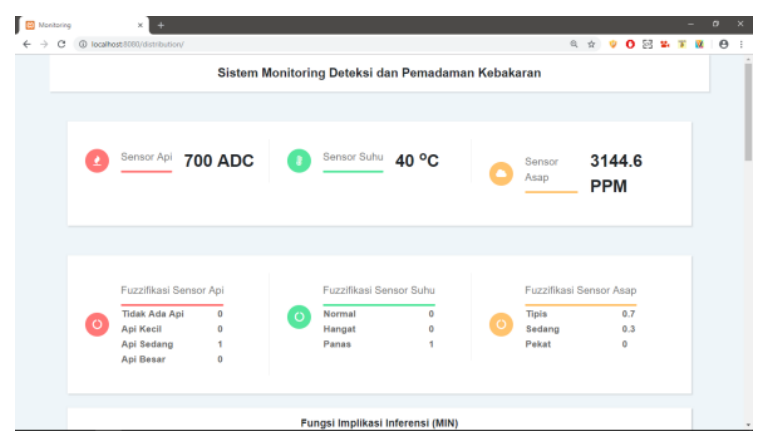

$\overline{\text { Gambar 13. Tampilan user interface web monitoring }}$

\section{Pengujian}

Pengujian ini meliputi pengujian pembacaan sensor suhu DHT22, sensor asap MQ-2, sensor api 5
Channel, pengujian notifikasi telegram, dan pengujian sistem metode Fuzzy Sugeno.

- Pengujian sensor DHT22

Pengujian sensor suhu DHT22 dibandingkan dengan hasil pengukuran menggunakan termometer digital. Pengujian dilakukan dengan menggunakan es dan uap air hangat untuk mendapatkan intensitas suhu, sehingga menghasilkan perbandingan sebagai berikut:

Tabel 2. Hasil Pengujian Sensor DHT22 dan Termometer

$\begin{array}{lllll}\text { No } & \text { Kondi } & \begin{array}{l}\text { Senso } \\ \text { r }\end{array} & \begin{array}{l}\text { Termo } \\ \text { meter }\end{array} & \begin{array}{l}\text { Perhitunga } \\ \text { n }\end{array} \\ & & \text { DHTPE }\end{array}$

Diperoleh nilai rata-rata error antara pengukuran akuisisi sensor suhu DHT22 dan thermometer digital adalah $3 \%$ dari 15 kali pengujian.

- Pengujian sensor asap MQ-2

Pengujian pembacaan asap menggunakan obat nyamuk bakar kertas untuk menaikkan intensitas kadar asap yang diterima sensor dengan nilai satuan PPM (Part Per Million) dan nilai analog ADC sehingga didapat hasil pembacaan sensor pada tabel berikut:

Tabel 3. Hasil Pengujian Sensor MQ-2

$\begin{array}{llll}\text { No. } & \text { Kondisi Asap } & \begin{array}{c}\text { Sensor } \\ \text { MQ-2 } \\ \text { (ADC) }\end{array} & \begin{array}{l}\text { Sensor } \\ \text { MQ-2 } \\ \text { (PPM) }\end{array} \\ \text { 1. } & & 85 & 0.00 \\ \text { 2. } & & 78 & 0.00 \\ \text { 3. } & \text { Belum ada asap } & 74 & 0.00 \\ \text { 4. } & & 74 & 0.00 \\ \text { 5. } & & 75 & 0.00 \\ \text { 6. } & & 182 & 18.00 \\ \text { 7. } & \text { Asap mulai pekat } & 193 & 28.00 \\ \text { 8. } & \text { menyebar } & 184 & 19.00 \\ \text { 9. } & \text { disekitar sensor } & 186 & 19.00 \\ \text { 10. } & & 214 & 41.00\end{array}$




$\begin{array}{llll}\text { 11. } & & 99 & 0.00 \\ \text { 12. } & \text { Asap mulai } & 97 & 0.00 \\ \text { 13. } & \text { terurai menipis } & 176 & 6.00 \\ \text { 14. } & & 99 & 0.00 \\ 15 . & & 174 & 1.00\end{array}$

Berlandaskan hasil pembacaan sensor menunjukkan bahwa kadar asap pada sensor MQ-2 dengan hasil nilai satuan PPM serta nilai analog ADC mengalami perubahan naik turun sesuai asap yang menyebar.

- Pengujian sensor api 5 channel

Pengukuran menghasilkan nilai data analog ADC. Pengukuran juga dilakukan dengan menggunakan alat ukur digital lux meter untuk mengetahui intesitas cahaya yang ditangkap. Tahap pengujian sensor api 5 channel menggunakan parameter jarak tertentu dengan beberapa lilin untuk menaikkan intensitas api.

Tabel 4. Hasil Pengujian Sensor Api 5 Channel

\begin{tabular}{|c|c|c|c|c|c|c|c|c|}
\hline \multirow[b]{2}{*}{$\mathbf{N}$} & \multirow{3}{*}{$\begin{array}{l}\text { Jar } \\
\text { ak }\end{array}$} & \multirow{3}{*}{$\begin{array}{l}\text { Juml } \\
\text { ah }\end{array}$} & \multicolumn{5}{|c|}{ Sensor Api 5 Channel } & \multirow{2}{*}{$\begin{array}{l}\text { lux } \\
\text { met } \\
\text { er }\end{array}$} \\
\hline & & & C & C & C & C & $\mathbf{C}$ & \\
\hline & & & 1 & 2 & 3 & 4 & 5 & (Lu \\
\hline & & & & & & & & \\
\hline \multirow[t]{2}{*}{1.} & 50 & 1 lilin & 10 & 11 & 48 & 26 & 11 & 12.2 \\
\hline & $\mathrm{cm}$ & & 5 & 8 & 9 & 7 & 0 & \\
\hline \multirow[t]{2}{*}{2.} & & 2 lilin & 12 & 14 & 67 & 34 & 13 & 14.1 \\
\hline & & & 8 & 8 & 6 & 7 & 7 & \\
\hline \multirow[t]{2}{*}{3.} & & 3 lilin & 18 & 21 & 75 & 42 & 19 & 18.7 \\
\hline & & & 6 & 3 & 6 & 2 & 7 & \\
\hline \multirow[t]{2}{*}{4.} & 100 & 1 lilin & 70 & 87 & 17 & 60 & 79 & 11.6 \\
\hline & $\mathrm{cm}$ & & & & 9 & & & \\
\hline \multirow[t]{2}{*}{5.} & & 2 lilin & 10 & 12 & 36 & 16 & 10 & 13.2 \\
\hline & & & 0 & 7 & 8 & 8 & 9 & \\
\hline \multirow[t]{2}{*}{6.} & & 3 lilin & 18 & 23 & 49 & 28 & 20 & 14.8 \\
\hline & & & 7 & 7 & 2 & 5 & 4 & \\
\hline \multirow[t]{2}{*}{7.} & 150 & 1 lilin & 41 & 47 & 16 & 10 & 46 & 10.5 \\
\hline & $\mathrm{cm}$ & & & & 7 & 0 & & \\
\hline \multirow[t]{2}{*}{8.} & & 2 lilin & 94 & 11 & 31 & 11 & 10 & 11.2 \\
\hline & & & & 5 & 9 & 3 & 8 & \\
\hline \multirow[t]{2}{*}{9.} & & 3 lilin & 11 & 14 & 33 & 16 & 13 & 12.2 \\
\hline & & & 5 & 0 & 3 & 4 & 1 & \\
\hline
\end{tabular}

Hasil perbandingan diatas menunjukkan kenaikan nilai intensitas api dari sensor api maupun digital lux meter ketika ditambah menjadi dua dan tiga lilin pada rentang jarak mulai $50 \mathrm{~cm}, 100 \mathrm{~cm}$, dan $150 \mathrm{~cm}$.

- Pengujian notifikasi telegram

Hasil pengujian pada sistem notifikasi telegram berjalan sesuai rencana, Bot (Robot) dari telegram akan mengirikman pesan apabila terjadi kondisi berasap, kondisi siaga dan kondisi kebakaran sehingga dapat memberikan informasi kondisi yang sedang terjadi. Script program untuk mengirimkan pesan notifikasi akan di eksekusi apabila output dari perhitungan metode Fuzzy Sugeno menghasilkan

nilai yang sesuai dengan beberapa kondisi yaitu berasap, siaga atau kebakaran.

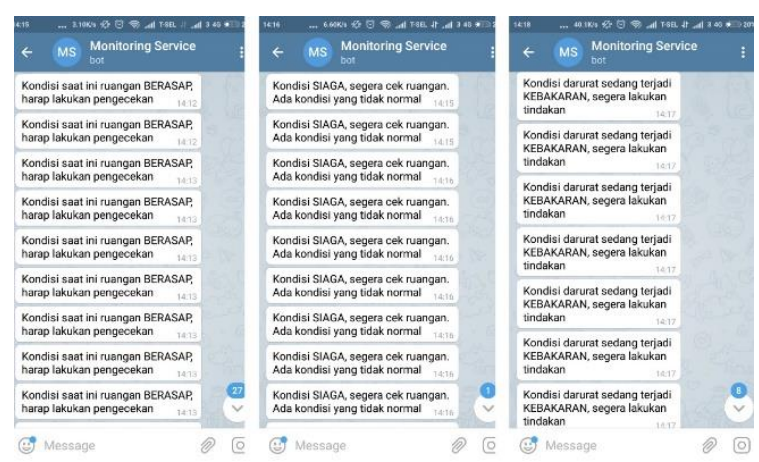

Gambar 14. Pesan notifikasi sesuai kondisi tertentu

- $\quad$ pengujian Metode Fuzzy Sugeno

Pada pengujian respon sistem dibuat beberapa simulasi kondisi normal, berasap, siaga dan kebakaran yaitu dengan menggunakan air hangat untuk menaikkan suhu, menggunakan obat nyamuk bakar untuk meningkatkan intensitas kepekatan asap dan menggunakan lilin sebagai sumber api. Hasil pengujian respon sistem Fuzzy Sugeno disajikan dalam tabel berikut:

Tabel 5. Hasil Pengujian Respon Sistem

\begin{tabular}{|c|c|c|c|c|c|c|c|}
\hline \multirow[t]{2}{*}{$\begin{array}{l}\mathbf{N} \\
\mathbf{0}\end{array}$} & \multirow[t]{2}{*}{$\begin{array}{l}\text { Su } \\
\text { hu }\end{array}$} & \multirow[t]{2}{*}{$\begin{array}{l}\text { As } \\
\text { ap }\end{array}$} & \multirow[t]{2}{*}{$\begin{array}{l}\text { A } \\
\text { pi }\end{array}$} & \multicolumn{2}{|c|}{$\begin{array}{l}\text { Deffuzifika } \\
\text { si }\end{array}$} & \multirow[t]{2}{*}{$\begin{array}{l}\text { Kondi } \\
\text { si }\end{array}$} & $\begin{array}{l}\text { Fals } \\
\text { e } \\
\text { Alar } \\
\text { m }\end{array}$ \\
\hline & & & & $\begin{array}{l}\text { Man } \\
\text { ual }\end{array}$ & $\begin{array}{l}\text { Sist } \\
\text { em }\end{array}$ & & $\begin{array}{ll}\mathbf{Y} & \mathbf{N}\end{array}$ \\
\hline 1 & $\begin{array}{l}33 . \\
1\end{array}$ & $\begin{array}{l}36 \\
7\end{array}$ & 74 & 1.31 & 1.31 & $\begin{array}{l}\text { Berasa } \\
\mathrm{p}\end{array}$ & $\checkmark$ \\
\hline 2 & $\begin{array}{l}33 . \\
0\end{array}$ & $\begin{array}{l}81 \\
1\end{array}$ & 80 & 1.30 & 1.30 & $\begin{array}{l}\text { Berasa } \\
\mathrm{p}\end{array}$ & $\checkmark$ \\
\hline 3 & $\begin{array}{l}28 . \\
5\end{array}$ & 25 & 54 & 0.00 & 0.00 & $\begin{array}{l}\text { Norma } \\
1\end{array}$ & $\checkmark$ \\
\hline 4 & $\begin{array}{l}29 . \\
1\end{array}$ & 23 & $\begin{array}{l}97 \\
6\end{array}$ & 2.00 & 2.00 & Siaga & $\checkmark$ \\
\hline 5 & $\begin{array}{l}32 . \\
6\end{array}$ & $\begin{array}{l}58 \\
3\end{array}$ & $\begin{array}{l}97 \\
6\end{array}$ & 3.00 & 3.00 & $\begin{array}{l}\text { Kebak } \\
\text { aran }\end{array}$ & $\checkmark$ \\
\hline 6 & $\begin{array}{l}27 . \\
5\end{array}$ & 0 & 39 & 0.00 & 0.00 & $\begin{array}{l}\text { Norma } \\
1\end{array}$ & $\checkmark$ \\
\hline 7 & $\begin{array}{l}31 . \\
1\end{array}$ & 0 & $\begin{array}{l}97 \\
9\end{array}$ & 2.10 & 2.10 & Siaga & $\checkmark$ \\
\hline 8 & $\begin{array}{l}32 . \\
1\end{array}$ & $\begin{array}{l}11 \\
9\end{array}$ & $\begin{array}{l}97 \\
5\end{array}$ & 3.00 & 3.00 & $\begin{array}{l}\text { Kebak } \\
\text { aran }\end{array}$ & $\checkmark$ \\
\hline 9 & $\begin{array}{l}30 . \\
9\end{array}$ & $\begin{array}{l}70 \\
2\end{array}$ & 82 & 1.10 & 1.10 & $\begin{array}{l}\text { Berasa } \\
\mathrm{p}\end{array}$ & $\checkmark$ \\
\hline $\begin{array}{l}1 \\
0\end{array}$ & $\begin{array}{l}34 . \\
2\end{array}$ & 0 & $\begin{array}{l}98 \\
3\end{array}$ & 2.40 & 2.40 & Siaga & $\checkmark$ \\
\hline 1 & 32. & 13 & 74 & 1.25 & 1.25 & Berasa & $\checkmark$ \\
\hline $\begin{array}{l}1 \\
1\end{array}$ & 30. & 27 & 54 & 0.08 & 0.08 & Norma & $\checkmark$ \\
\hline 1 & $\begin{array}{l}0 \\
32 .\end{array}$ & 25 & 97 & 2.22 & 2.22 & $\begin{array}{l}\text { Siaga } \\
\text { Sil }\end{array}$ & $\checkmark$ \\
\hline 3 & 2 & & 2 & & & & \\
\hline 1 & 32. & 70 & 97 & 3.00 & 3.00 & Kebak & $\checkmark$ \\
\hline
\end{tabular}




$\begin{array}{lllllll}4 & 5 & 2 & 6 & & & \text { aran } \\ 1 & 28 . & 70 & 97 & 2.80 & 2.80 & \text { Kebak } \\ 5 & 0 & & 2 & & & \text { aran }\end{array}$

Pengujian pada tabel diatas dilakukan simulasi secara acak beberapa kondisi normal, berasap, siaga dan kebakaran dengan menggunakan air hangat, beberapa buah lilin serta obat nyamuk bakar. Berdasarkan dari 15 kali pengujian menghasilkan nilai respon sistem yang sesuai dengan kondisi pada metode Fuzzy Sugeno serta tanpa adanya false alarm yang terjadi. Nilai proses deffuzifikasi dari perhitungan metode Fuzzy Sugeno secara manual maupun perhitungan sistem menghasilkan nilai yang sama tanpa selisih. Hasil dari pengujian nilai akurasi metode Fuzzy Sugeno adalah sebagai berikut:

Tabel 6. Nilai Akurasi Pengujian Metode Fuzzy Sugeno

\begin{tabular}{|l|l|}
\hline Jumlah Pengujian & 15 \\
\hline Nilai Deffuzifikasi Sesuai & 15 \\
\hline Nilai Deffuzifikasi Tidak Sesuai & 0 \\
\hline False Alarm & 0 \\
\hline Tingkat Akurasi Perhitungan & $100 \%$ \\
\hline
\end{tabular}

Perhitungan dari deffuzifikasi menghasilkan beberapa nilai output yang berbeda namun memiliki kondisi yang sama karena nilai tersebut masih dalam rentang nilai kondisi yang telah ditentukan. Tabel perbandingan hasil defuzzifikasi manual dan sistem adalah sebagai berikut:

Tabel 7. Perbandingan Nilai Hasil Deffuzifikasi

\begin{tabular}{llll} 
No. & Kondisi & \multicolumn{2}{c}{$\begin{array}{l}\text { Deffuzifikasi } \\
\text { Manual }\end{array}$} \\
1. & & Sistem \\
2. & Normal & 0.00 & 0.00 \\
3. & & 0.00 & 0.00 \\
4. & & 0.08 & 0.08 \\
5. & & 1.31 & 1.31 \\
6. & Berasap & 1.30 & 1.30 \\
7. & & 1.10 & 1.10 \\
8. & & 1.25 & 1.25 \\
9. & & 2.00 & 2.00 \\
10. & Siaga & 2.10 & 2.10 \\
11. & & 2.40 & 2.40 \\
12. & & 2.22 & 2.22 \\
13. & & 3.00 & 3.00 \\
14. & Kebakaran & 3.00 & 3.00 \\
15. & & 3.00 & 3.00 \\
\end{tabular}

Berdasarkan hasil pengujian terhadap respon sistem metode Fuzzy Sugeno diatas menunjukkan nilai dari berbagai kondisi yang timbul. Kondisi normal dengan nilai $0.00,0.00$ dan 0.08 sesuai dengan rentang nilai defuzzifikasi yaitu mulai 0 sampai $\leq 0.5$, kondisi berasap dengan nilai $1.31,1$. 30, 1. 10 dan 1. 25 sesuai dengan rentang nilai defuzzifikasi yaitu mulai $>0.5$ sampai $\leq 1$. 5 . Kondisi siaga dengan nilai 2. 00, 2. 10, 2. 40 dan 2.
22 sesuai dengan rentang nilai defuzzifikasi $>1.5$ sampai $\leq 2.5$ serta pada kondisi kebakaran dengan nilai 3. 00, 3. 00, 3. 00 dan 2. 80 sesuai dengan rentang nilai defuzzifikasi $\geq 2.5$ sampai $\leq 3$.

\section{Kesimpulan}

Dari keseluruhan hasil penelitian yang telah dilakukan, maka dapat ditarik beberapa kesimpulan sebagai berikut:

1. Metode Fuzzy Sugeno dapat diterapkan dan digunakan untuk melakukan pendeteksian kebakaran berdasarkan parameter suhu, kadar asap dan intensitas api.

2. Sistem dapat melakukan pendeteksian terhadap beberapa kondisi yaitu normal, berasap, siaga dan kebekaran pada prototype sebagai simulasi kebakaran.

3. Pada kondisi normal sistem tidak memberikan respon, pada kondisi berasap sistem mengirimkan pesan melalui telegram, pada kondisi siaga sistem mengirim pesan telegram dan membunyikan buzzer, sedangkan pada kondisi kebakaran akan membunyikan buzzer dan menghidupkan pompa air serta mengirimkan pesan notifikasi melalui telegram.

4. Sistem melakukan input sensor data kedalam database dan melakukan perhitungan dengan metode Fuzzy Sugeno setiap lima detik sekali.

5. Berdasarkan hasil perhitungan metode Fuzzy Sugeno dengan cara manual maupun sistem menunjukkan nilai yang sama sehingga menjadi tolok ukur berhasilnya implementasi metode Fuzzy Sugeno.

6. Hasil pengujian respon sistem dari 15 kali percobaan dengan nilai data sensor yang berbeda menunjukkan hasil $100 \%$ sesuai dengan kondisi pada metode Fuzzy Sugeno serta tanpa adanya false alarm.

\section{Daftar Pustaka:}

G. Eason, B. Noble, and I.N. Sneddon, "On certain integrals of Lipschitz-Hankel type involving products of Bessel functions," Phil. Trans. Roy. Soc. London, vol. A247, pp. 529-551, April 1955. (references)

J. Clerk Maxwell, "A Treatise on Electricity and Magnetism," 3rd ed., vol. 2. Oxford: Clarendon, 1892, pp.68-73.

I.S. Jacobs and C.P. Bean, "Fine particles, thin films and exchange anisotropy," in Magnetism, vol. III, G.T. Rado and H. Suhl, Eds. New York: Academic, 1963, pp. 271-350.

K. Elissa, "Title of paper if known," belum dipublikasikan.

R. Nicole, "Title of paper with only first word capitalized," J. Name Stand. Abbrev., in press. 